\title{
Anatomia foliar com implicações taxonômicas em espécies de ipês
}

\author{
Andréa Monte Luchiari da Silva ${ }^{1}$, Marina Fernanda Bortolin Costa ${ }^{1}$, Viviane Gonçalves Leite ${ }^{1}$, \\ Andréia Alves Rezende ${ }^{2}$ e Simone de Pádua Teixeira ${ }^{1,3}$
}

Recebido: 12.11.2008; aceito: 14.05.2009

\begin{abstract}
Leaf anatomy with taxonomic implications in "ipê" species). By considering that Brazilian species of Ipês are hardly identified when in vegetative stage, the present study aims to research foliar anatomic characters that might allow recognize medicinal ipê species. Leaves of six species of Handroanthus (yellow flowers: H. chrysotrichus, H. ochraceus and $H$. serratifolius; white flowers: $H$. roseo-albus; purple flowers: $H$. heptaphyllus and $H$. impetiginosus) and one species of Tabebuia (yellow flowers: T. aurea) were prepared to be observed with light microscopy (free-hand cuts), and scanning electronic microscopy (surface analysis). Foliar anatomical characters allow recognizing Ipê species. The better ones provided by foliar lamina were the number of epidermic layers, the stomata position in relation to the other epidermic cells, the occurrence of domatia, the parechymatic cell wall thickening in the margin, the mesophyll type and the presence of paraveinal parenchyma; in the petiole, we can cite the petiole shape, the epidermic cell shape and the occurrence of inner phloematic fibers.
\end{abstract}

Key words: Bignoniaceae, diagnostic character, Handroanthus, Tabebuia

RESUMO - (Anatomia foliar com implicações taxonômicas em espécies de ipês). Tendo em vista a dificuldade de identificação dos ipês brasileiros em estado vegetativo, este trabalho objetivou levantar caracteres que possibilitassem reconhecê-los pela anatomia foliar (lâmina foliar e pecíolo). Folhas de seis espécies de Handroanthus (ipês amarelos: H. chrysotrichus, $H$. ochraceus e H. serratifolius; ipê branco: H. roseo-albus; ipês roxos: H. heptaphyllus e H. impetiginosus) e de uma espécie de Tabebuia (ipês amarelo: T. aurea) foram preparadas para observação em microscopias de luz (exame histológico) e eletrônica de varredura (exame de superfície). Caracteres provenientes da anatomia foliar possibilitaram a diagnose dos ipês, sendo mais relevantes na lâmina foliar, o número de camadas da epiderme, a posição dos estômatos em relação às demais células epidérmicas, a presença de domácias, a presença de espessamento de parede das células parenquimáticas na margem, o tipo de mesofilo e a presença de parênquima paravenal; no pecíolo, destacaram-se seu formato, a forma das células epidérmicas e a presença de fibras na região interna do floema.

Palavras-chave: Bignoniaceae, caráter diagnóstico, Handroanthus, Tabebuia

\section{Introdução}

Bignoniaceae é uma família de distribuição pantropical, com cerca de 120 gêneros e 800 espécies; entre elas, 100 são conhecidas popularmente como ipês, incluídas atualmente nos gêneros Handroanthus e Tabebuia e encontradas principalmente nas regiões neotropicais (Souza \& Lorenzi 2005, Olmstead \& Grose 2007).

Os ipês são muito utilizados na ornamentação urbana devido à beleza de seu porte e de suas flores (Lorenzi 2002), que podem ser brancas, amarelas e roxas. São também conhecidos pelas propriedades medicinais de algumas espécies: Handroanthus impetiginosus (Mart. ex DC.) Mattos (ipê roxo); $H$. ochraceus (Cham.) Mattos, H. serratifolius (Vahl.) S.O. Grose e Tabebuia aurea (Silva Manso) Benth. \& Hook.f.ex S. Moore (ipês amarelos); e H.roseo-albus (Ridl.) Mattos (ipê branco) (Rodrigues \& Carvalho 2001, Lorenzi \& Matos 2002). Não há relatos de emprego medicinal para H. chrysotrichus (Mart.ex A. DC.) Mattos (ipês amarelo) e H. heptaphyllus (Vell.) Mattos (ipê roxo).

As espécies de ipês foram incluídas, por muito tempo, em Tabebuia, apesar das divergências na circunscrição taxonômica desse gênero. No entanto, estudos recentes de filogenia molecular mostraram que Tabebuia é polifilético (Olmstead \& Grose 2007). Inicialmente, o nome Tabebuia incluía apenas as Bignonieae arbóreas com folhas simples (De Candolle

1. Universidade de São Paulo, Faculdade de Ciências Farmacêuticas de Ribeirão Preto, Departamento de Ciências Farmacêuticas, Av. do Café, s/nº, 14040-903 Ribeirão Preto, SP, Brasil

2. Centro Universitário de Rio Preto, Rua Yvette Gabriel Atique, 45, 15025-400 São José do Rio Preto, SP, Brasil

3. Autor para correspondência: spadua@fcfrp.usp.br 
1838); posteriormente, Tabebuia foi expandido, compreendendo representantes de Tecoma (Britton 1915). A grande quantidade de morfo-espécies e, portanto, a variedade morfológica, gerou muitos sinônimos no grupo (Gentry 1992, Lorenzi 2002). Mattos (1970) apud Olmstead \& Grose (2007), baseando-se na circunscrição original de Tabebuia dividiu as espécies desse gênero em Handroanthus e Tabebuia, propondo o reconhecimento do grupo brasileiro de ipês como membros de Handroanthus. Em 1992, Gentry incluiu novamente as espécies de Handroanthus em Tabebuia e reconheceu neste gênero três clados que, de acordo com Olmstead \& Grose (2007), incluem os táxons anteriormente segregados. Esses clados foram separados na chave de identificação de Gentry (1992), na qual foram utilizados muitos caracteres morfológicos quantitativos, gerando dificuldade na identificação das espécies, em especial, devido à sobreposição de muitos desses caracteres.

Poucos estudos tratam da anatomia de representantes de Bignoniaceae. Pode-se citar Metcalfe \& Chalk (1950), que caracterizaram alguns representantes da família; Souza \& Oliveira (2004) que estudaram plântulas de $H$. impetiginosus $(=T$. avellanedae) e $H$. chrysotrichus $(=T$. chrysotricha); Souza et al. (2005), que estudaram fruto e semente de H. chrysotrichus; Sampaio et al. (2007), que estudaram a ontogenia da semente de H. ochraceus; e Dousseau et al. (2008) que compararam a folha de plantas de $H$. serratifolius $(=T$. serratifolia $)$ propagadas in vivo, in vitro e durante a aclimatização. Tais trabalhos, se comparados a outros com espécies de ipês, poderiam auxiliar na delimitação taxonômica deste grupo.

Considerando as divergências taxonômicas acerca dos gêneros Handroanthus e Tabebuia, a escassez de trabalhos anatômicos do grupo e a dificuldade de identificação das espécies em estado vegetativo, o objetivo do presente trabalho foi verificar se caracteres anatômicos da folha podem ser utilizados na diagnose de sete espécies brasileiras de ipês (Handroanthus chrysotrichus, $H$. heptaphyllus, H. impetiginosus, H. ochraceus, H. roseoalbus, H. serratifolius e Tabebuia aurea), auxiliando, assim, estudos taxonômicos do grupo.

\section{Material e métodos}

Folhas das espécies de Handroanthus foram coletadas de árvores cultivadas no município de Ribeirão Preto, SP, e de Tabebuia aurea nos arredores de Botucatu, SP. Pelo menos dois indivíduos foram utilizados por espécie.
Materiais testemunha de Handroanthus foram depositados no herbário SPFR, da Faculdade de Filosofia, Ciências e Letras de Ribeirão Preto/ USP, São Paulo, Brasil, sob os seguintes registros: H. chrysotrichus - S.P. Teixeira 19, M.F.B. Costa \& V.G. Leite; S.P. Teixeira 20, V.G. Leite, M.F.B. Costa \& A.M.L. Silva; H. heptaphyllus - S.P. Teixeira 27, M.F.B. Costa, A.M.L. Silva \& E. Campos; S.P. Teixeira 30, M.F.B. Costa, A.M.L. Silva \& E. Campos; H. impetiginosus - S.P. Teixeira 17, M.F.B.Costa \& M.S. Ogasawara; H.ochraceus - S.P. Teixeira 22, A.M.L. Silva \& M.S. Ogasawara; H. roseo-albus - S.P. Teixeira 24, M.F.B. Costa \& A.M.L. Silva; S.P. Teixeira 29, M.F.B. Costa, A.M.L. Silva \& E. Campos; H. serratifolius - S.P. Teixeira 23, M.F.B. Costa \& A.M.L. Silva. Material testemunha de Tabebuia aurea foi depositado no herbário BOTU, do Instituto de Biociências da UNESP, campus de Botucatu, São Paulo, Brasil, sob o registro Gottsberger 18872.

Aidentificação das espécies estudadas foi efetuada seguindo as descrições e chaves de identificação de Gentry (1992) e de Olmstead \& Grose (2007). Os nomes científicos foram verificados na página eletrônica mobot.mobot.org/W3T/Search/vast.html.

Partes da lâmina foliar (ápice, base, terço médio e margem) e do pecíolo (terço médio), com cerca de $1 \mathrm{~cm}^{2}$, foram fixadas em FNT (Johansen 1940), submetidas à desidratação etanólica gradativa e armazenadas em etanol $70 \%$. Parte do material fixado foi destinada ao exame de superfície em microscopia eletrônica de varredura e parte à análise anatômica em microscopia de luz.

Para o exame de superfície, materiais provenientes da lâmina foliar, com cerca de $1 \mathrm{~cm}^{2}$, foram desidratadas em série etanólica, submetidas a ponto crítico em aparelho Balzers CPD 030, afixadas em suportes metálicos, com fita adesiva de Carbono e, então, cobertas com Ouro em um metalizador (Balzers SCD 050). As observações foram efetuadas em Microscópio Eletrônico de Varredura (JEOL JSM5200 ) em $25 \mathrm{KV}$, e as eletromicrografias obtidas com câmera fotográfica (JEOL MP).

Para o estudo anatômico foram confeccionadas lâminas histológicas semi-permanentes e permanentes da lâmina foliar e do pecíolo. As semi-permanentes foram obtidas a partir do seccionamento do material à mão, coloração com uma mistura de azul de astra e safranina (Gerlach 1969) e sudam III (Johansen 1940) e montagem em gelatina glicerinada. As lâminas permanentes foram obtidas a partir da inclusão do 
material em parafina, utilizando xilol como solvente; seccionamento em micrótomo rotativo $(6$ a $8 \mu \mathrm{m})$, coloração com uma mistura de azul de astra e safranina e montagem em resina sintética (Gerlach 1969). As lâminas foram observadas em microscópio de luz e as fotomicrografias obtidas em fotomicroscópio Leica DM 500, com as escalas nas mesmas condições ópticas.

\section{Resultados}

Pecíolo - O formato do pecíolo (figuras 1-7), em seção transversal, apresentou diferenças entre as espécies, sendo canaliculado em Handroanthus chrysotrichus (figura 1); cilíndrico em $H$. heptaphyllus (figura 2), $H$. impetiginosus (figura 3 ) e $H$. serratifolius (figura 4); achatado dorsiventralmente em $\mathrm{H}$. ochraceus (figura 5); e cilíndrico com duas projeções em $H$. roseo-albus (figura 6) e Tabebuia aurea (figura 7).

A epiderme é unisseriada (figuras 8-10), sendo constituída por células papilosas em $H$. chrysotrichus (figura 8) e T. aurea (figura 10), e retangulares em $H$. heptaphyllus, $H$. impetiginosus, $H$. ochraceus, $H$. roseo-albus (figura 9) e $\mathrm{H}$. serratifolius. O córtex é parenquimático (figuras 8-10). A unidade vascular central é contínua, com xilema interno ao floema, e periciclo esclerenquimático constituído de fibras (figuras 8-10). Handroanthus chrysotrichus é a única espécie que apresenta fibras dispostas em faixas contínuas na região do floema (figura 8). A medula é parenquimática em todas as espécies, sendo oca em $H$. heptaphyllus (figura 2) e $H$. impetiginosus (figura 3).

Lâmina foliar - A epiderme é cuticularizada, exibindo variações inter e intra-específicas em relação ao número de camadas (figuras 11-22): uni a bisseriada em H. chrysotrichus (figuras 11-12), H. heptaphyllus, $H$. serratifolius (figuras 21-22) e T. aurea; multisseriada na face adaxial e uni a bisseriada na face abaxial em $H$. impetiginosus (figuras 15-16), H. ochraceus (figuras 17-18) e H.roseo-albus (figuras 19-20).

Os estômatos ocorrem na face abaxial da lâmina foliar na maioria das espécies (figuras 11-22), exceto em $T$. aurea, que apresenta estômatos em ambas as faces (figuras 23-24). Os estômatos são protuberantes, localizados acima das demais células epidérmicas em H. chrysotrichus (figura 11), H. heptaphyllus (figura 13), H. impetiginosus (figura 15), H. ochraceus (figura 17) e H.roseo-albus (figura 20). Em $H$. serratifolius (figura 21) e T. aurea (figura 23) os estômatos estão localizados no mesmo nível das demais células epidérmicas.

As domácias, presentes em $H$. chrysotrichus, $H$. heptaphyllus, H.impetiginosus, H.roseo-albus (figura 25-26) e $H$. serratifolius, são observadas em toda a extensão da lâmina foliar, na face abaxial, na junção entre a nervura principal e as nervuras secundárias (figuras 25-26). São constituídas por depressões revestidas de tricomas tectores unicelulares filiformes (figura 26), que ocorrem em grande quantidade próximo à região da abertura da cripta.

Tricomas de formas variadas, cuticularizados, ocorrem por toda a extensão da lâmina foliar em todas as espécies, sendo escamiformes (figuras 27-30), estrelados (figuras 31), pateliformes (figuras 32, 33, 35,36 ) e em roseta (figuras 33,34 ).

O mesofilo é isolateral em $H$. chrysotrichus (figura 11), H.impetiginosus (figura 15), H.ochraceus (figura 17) e T. aurea (figura 23); e dorsiventral, com parênquima lacunoso exibindo espaços intercelulares amplos em $H$. heptaphyllus (figura 13), H. roseoalbus (figura 19) e H. serratifolius (figura 21). Em H. chrysotrichus (figura 11) ocorre parênquima paravenal. A face abaxial da lâmina foliar de $H$. chrysotrichus (figura 11) e H. ochraceus (figura 17) apresenta ondulações pronunciadas.

A margem foliar apresenta a cutícula mais espessa e as células epidérmicas são papilosas (figuras 10,12, 14, 16, 18, 20, 22, 24); as células subepidérmicas são parenquimáticas, exibindo paredes lignificadas em $H$. heptaphyllus (figura 14), H. ochraceus (figura 18), $H$. roseo-albus (figura 20), $H$. serratifolius (figura 22) e T. aurea (figura 24).

A nervura central apresenta epiderme unisseriada e cuticularizada em ambas as faces; o tecido subepidérmico é colenquimático e, mais internamente, parenquimático; a unidade vascular central é contínua, constituída de periciclo esclerenquimático (fibras), xilema interno ao floema, e medula, seguindo o padrão do pecíolo.

As nervuras secundárias são constituídas por feixes vasculares colaterais, delimitados por bainha parenquimática unisseriada - endoderme, sendo as extensões da bainha constituídas de fibras (figuras 1123). Em T. aurea as nervuras secundárias estão menos espaçadas (figura 23) que nas demais espécies.

A tabela 1 sintetiza as características anatômicas foliares com valor diagnóstico para as espécies de ipês estudadas. 

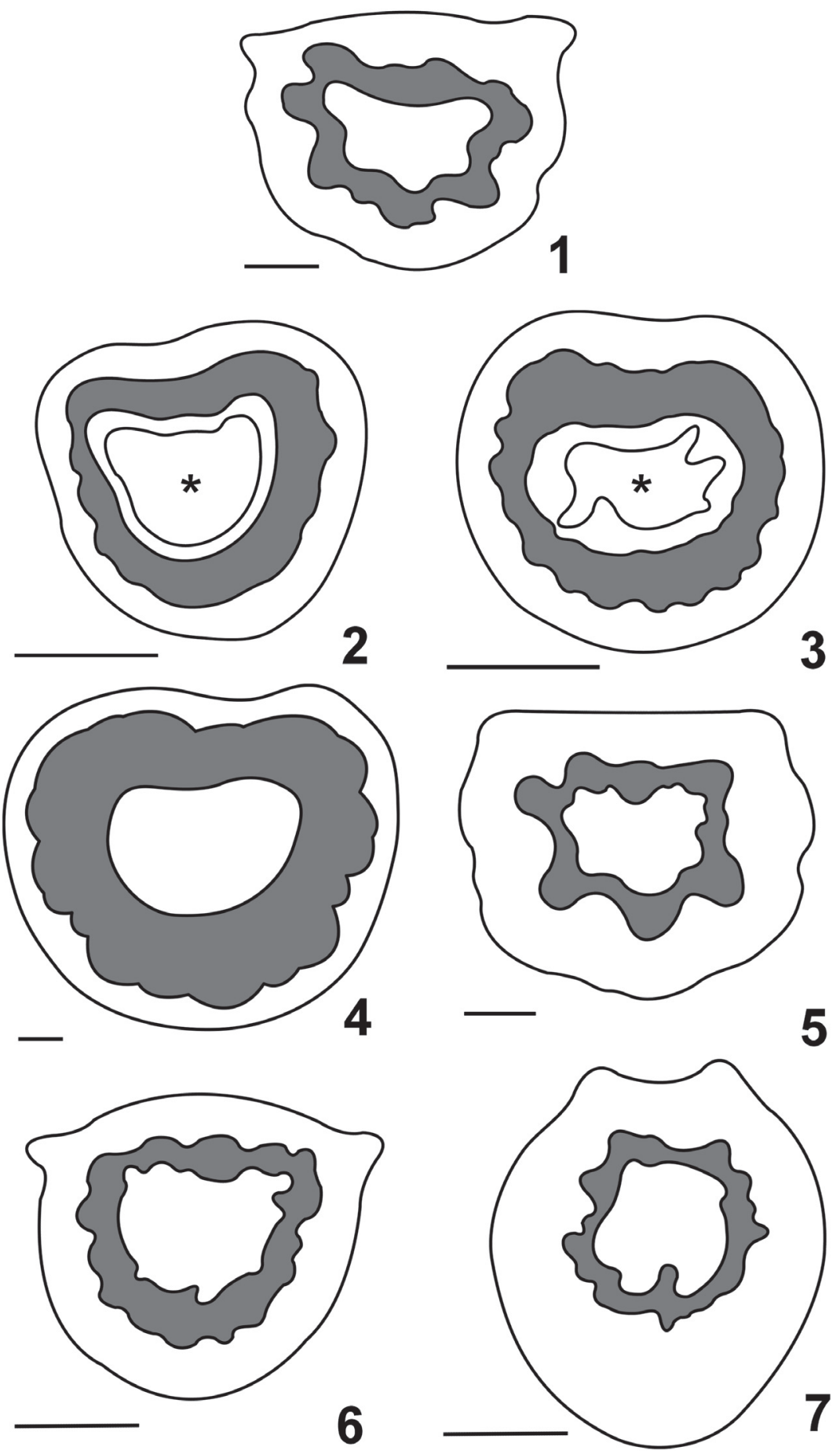

Figuras 1-7. Esquemas de seções transversais do pecíolo de espécies de Handroanthus e Tabebuia. Formato canaliculado em H. chrysotrichus (1); cilíndrico em H. heptaphyllus (2), H. impetiginosus (3) e H. serratifolius (4); achatado dorsiventralmente em H. ochraceus (5); e cilíndrico com duas projeções em H. roseo-albus (6) e T. aurea (7). * indica a medula oca e a região em cinza indica a unidade vascular. Barras $=230 \mu \mathrm{m}(1), 450 \mu \mathrm{m}(2,3), 100 \mu \mathrm{m}(4), 260 \mu \mathrm{m}(5), 400 \mu \mathrm{m}(6), 380 \mu \mathrm{m}(7)$.

Figures 1-7. Schematic drawings of petiole cross-sections of Handroanthus and Tabebuia species. Canaliculated petiole in H. chrysotrichus (1); cylindrical petiole in H. heptaphyllus (2), H. impetiginosus (3) and H. serratifolius (4); dorsiventral flattened petiole in H. ochraceus (5); and cylindrical petiole with two projections in H. roseo-albus (6) and T. aurea (7). * indicates the hollow medulla, and the grayish region indicates the vascular unit. Bars $=230 \mu \mathrm{m}(1), 450 \mu \mathrm{m}(2,3), 100 \mu \mathrm{m}$ (4), $260 \mu \mathrm{m}(5), 400 \mu \mathrm{m}(6), 380 \mu \mathrm{m}(7)$. 

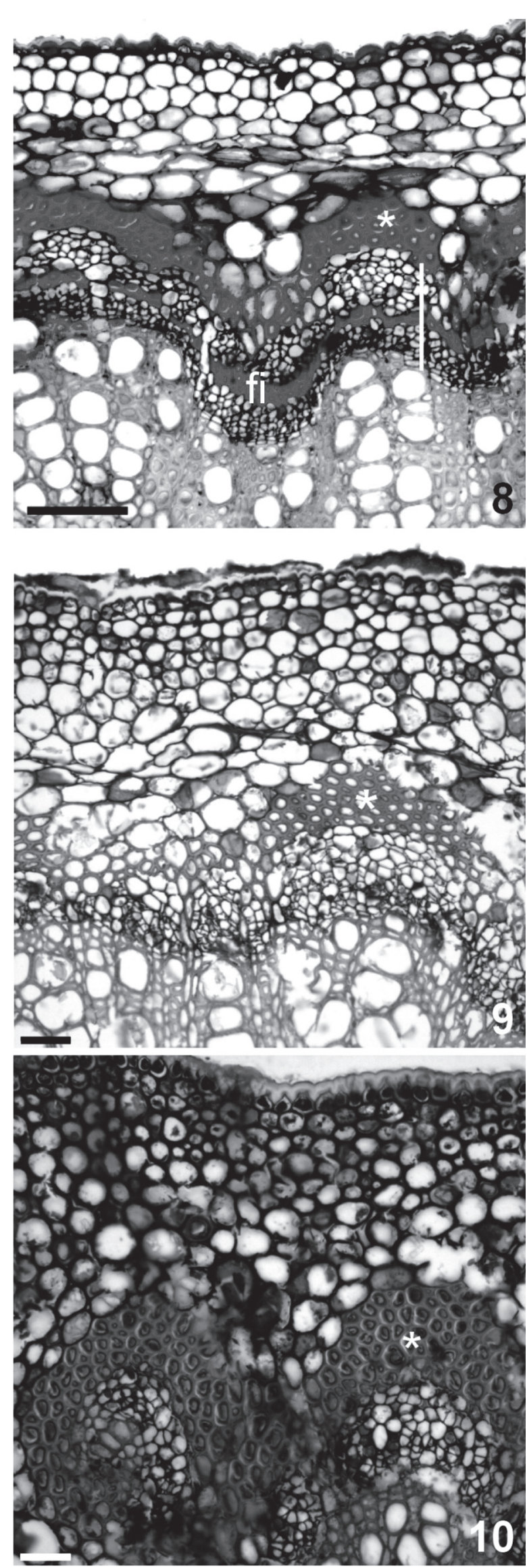

Figuras 8-10. Fotomicrografias de seções transversais do pecíolo de espécies de Handroanthus e Tabebuia. Observe a epiderme unisseriada, o córtex parenquimático e as fibras pericíclicas (*) delimitando o cilindro vascular constituído de xilema interno ao floema. 8. H. chrysotrichus. Detalhe da epiderme papilosa e das faixas de fibras (fi) localizadas internamente no floema (barra vertical). 9. H. roseo-albus. Detalhe da epiderme com células retangulares e da unidade vascular. 10. T. aurea. Detalhe da epiderme papilosa e da unidade vascular. Barras $=40 \mu \mathrm{m}$.

Figures 8-10. Photomicrographs of petiole cross-sections of Handroanthus and Tabebuia species. Observe the uniseriate epidermis, the parenchymatic cortex, and pericyclic fibres (*) surrounding the vascular unit, which is composed by inner xylem and outer phloem. 8.H.chrysotrichus. Detail of the papillose epidermis and of inner phloematic fibres (fi) (vertical bar). 9. H. roseo-albus. Detail of the rectangular epidermal cells and of the vascular unit. 10.T. aurea. Detail of the papillose epidermis and of the vascular unit. Bars $=40 \mu \mathrm{m}$.

\section{Discussão}

Várias características anatômicas foliares apresentaram valor diagnóstico para os ipês, principalmente se utilizadas em conjunto. Para o pecíolo, ressalta-se o formato, a presença de fibras floemáticas e de medula oca. Para a lâmina foliar podese citar a estratificação da epiderme, o tipo de mesofilo, a presença de parênquima paravenal, o tecido presente na margem da lâmina foliar e a posição dos estômatos em relação às demais células epidérmicas (ver tabela 1). Tabebuia aurea (ipê-amarelo medicinal) apresentou características exclusivas, como lâmina foliar anfiestomática e mesofilo com feixes vasculares pouco espaçados; Handroanthus chrysotrichus (ipê-amarelo sem emprego medicinal), apresentou parênquima paravenal no mesofilo, células parenquimáticas não lignificadas na margem e pecíolo canaliculado com fibras floemáticas; H. serratifolius (ipêamarelo medicinal) apresentou mesofilo dorsiventral, domácias e pecíolo cilíndrico; H. ochraceus (ipêamarelo medicinal), embora muito semelhante a $H$. chrysotrichus, se distinguiu por não apresentar epiderme uni a bisseriada e pela forma achatada do pecíolo; $H$. impetiginosus (ipê-roxo medicinal) e $H$. heptaphyllus (ipê-roxo sem emprego medicinal), embora bastante similares anatomicamente, podem ser diagnosticados pela ocorrência de mesofilo dorsiventral e pelo espessamento e lignificação da parede das células subepidérmicas (presentes em H. heptaphyllus e ausentes em $H$. impetiginosus); H. roseo-albus 

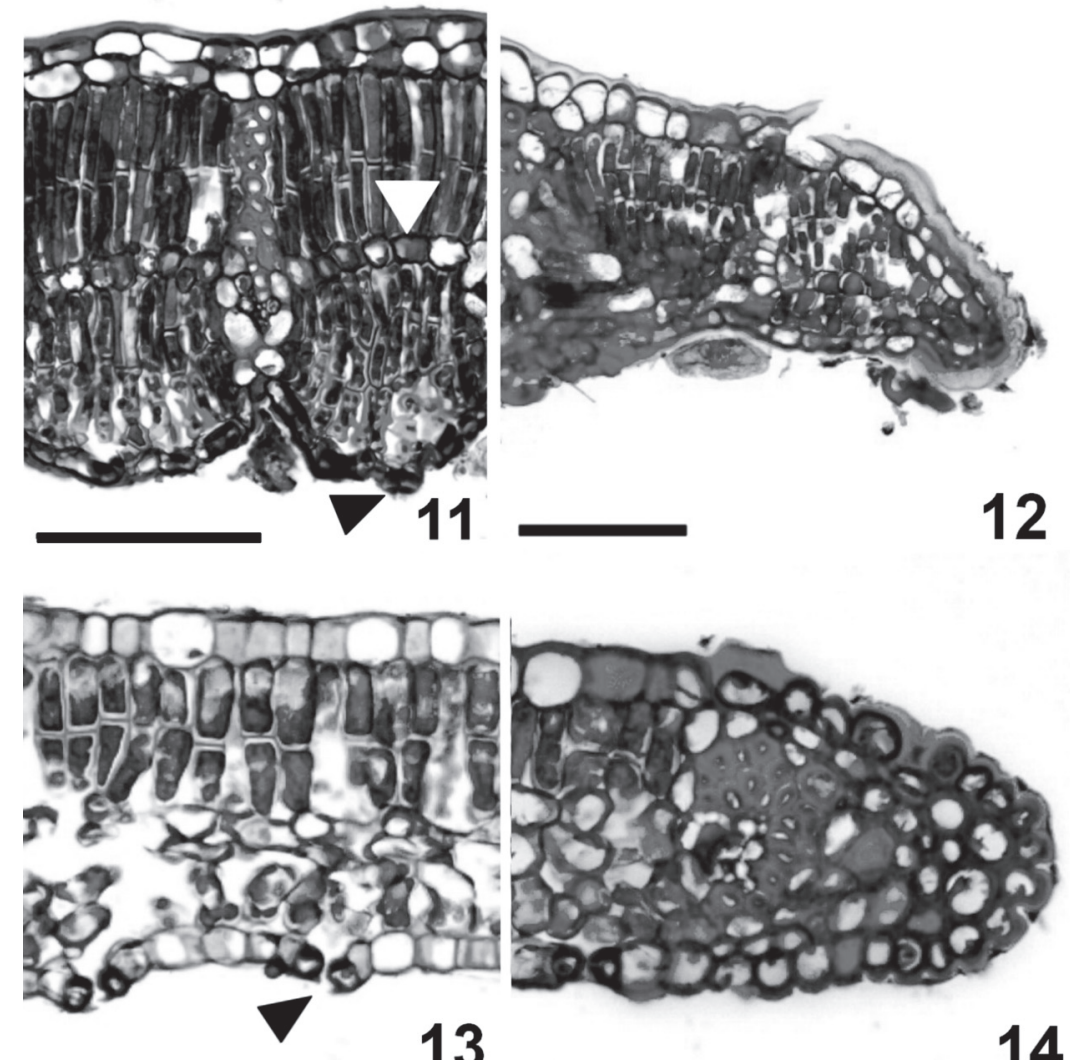

13

14

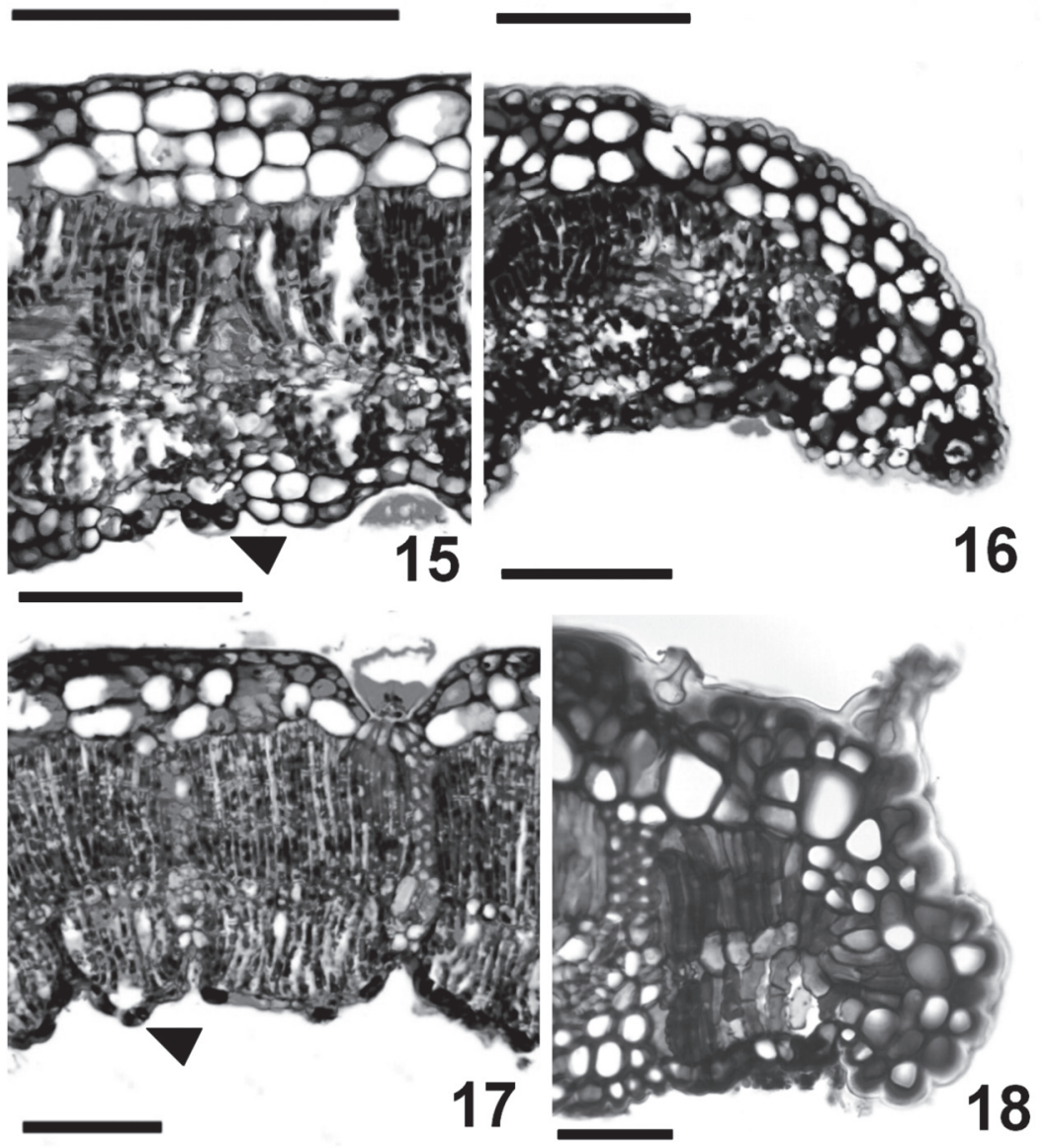

Figuras 11-18. Fotomicrografias de seções transversais da lâmina foliar de espécies de Handroanthus. 11-12. H. chrysotrichus. 11. Mesofilo isolateral. Note a epiderme bisseriada na face adaxial, um estômato protuberante (seta preta) na face abaxial e o parênquima paravenal (seta branca). 12. Margem com cutícula espessa e epiderme unisseriada na face adaxial. 13-14. H. heptaphyllus. 13. Mesofilo dorsiventral. Note a epiderme unisseriada e o estômato protuberante (seta). 14. Margem. Note as células subepidérmicas com paredes espessadas. 15-16. H. impetiginosus. 15. Mesofilo isolateral. Note a epiderme multisseriada na face adaxial e o estômato protuberante (seta) na face abaxial. 16. Margem. 17-18. H. ochraceus. 17. Mesofilo isolateral. Note a epiderme multisseriada na face adaxial e o estômato protuberante (seta) na face abaxial. 18. Margem. Note as células subepidérmicas com paredes espessadas. Barras $=50 \mu \mathrm{m}$.

Figures 11-18. Photomicrographs of leaf blade cross-sections of Handroanthus species. 11-12. H. chrysotrichus. 11. Isolateral mesophyll. Note the biseriate epidermis in the upper face, a raised stomatum (black arrow) in the lower face and the paraveinal parenchyma (white arrow). 12. Margin with thick cuticle and uniseriate epidermis in the upper face. 13-14. H. heptaphyllus. 13. Dorsiventral mesophyll. Note the uniseriate epidermis and a raised stomatum (arrow) in the lower face. 14. Margin. Note the thick-walled subepidermal cells. 15-16. $H$. impetiginosus. 15. Isolateral mesophyll. Note the multisseriate epidermis in the upper face and a raised stomatum (arrow) in the lower face. 16. Margin. 17-18. H. ochraceus. 17. Isolateral mesophyll. Note the multisseriate epidermis in the upper face and a raised stomatum (arrow) in the lower face. 18. Margin. Note the thick-walled subepidermal cells. Bars $=50 \mu \mathrm{m}$. 

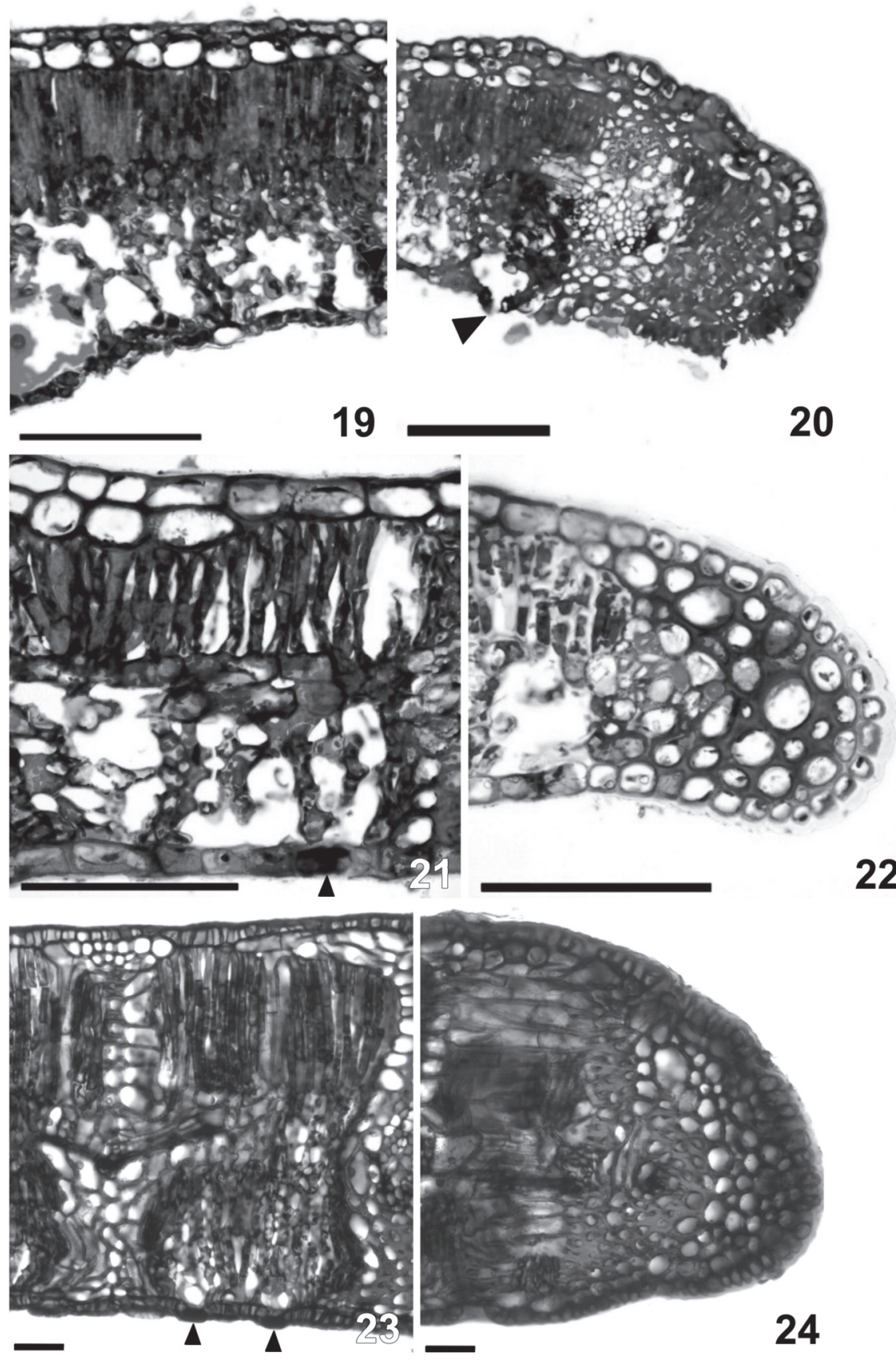

22

Figuras 19-24. Fotomicrografias de seções transversais da lâmina foliar de espécies de Handroanthus e Tabebuia. 19-20. H. roseo-albus. 19. Mesofilo dorsiventral. Note a epiderme multisseriada na face adaxial. 20. Margem. Note o estômato protuberante (seta) na face abaxial e as células subepidérmicas com paredes espessadas. 21-22. H. serratifolius. 21. Mesofilo dorsiventral. Note a epiderme bisseriada na face adaxial e os estômatos (seta) localizados no mesmo nível das demais células epidérmicas na face abaxial. 22. Margem. Note as células subepidérmicas com paredes espessadas.23-24. T. aurea.23. Mesofilo isolateral, anfiestomático, com nervuras secundárias pouco espaçadas entre si. Note os estômatos (setas) localizados no mesmo nível das demais células epidérmicas 24. Margem. Note as células subepidérmicas com paredes espessadas. Barras $=50 \mu \mathrm{m}$.

Figures 19-24. Photomicrographs of leaf blade cross-sections of Handroanthus and Tabebuia species. 19-20. H.roseo-albus. 19. Dorsiventral mesophyll. Note the multisseriate epidermis in the upper face. 20. Margin. Note the raised stomatum (arrow) in the lower face and the thick-walled subepidermal cells. 21-22. H. serratifolius. 21. Dorsiventral mesophyll. Note the biseriate epidermis in the upper face and stomatum (arrow) at the same level of the other epidermal cells in the lower face. 22. Margin. Note the thick-walled subepidermal cells. 23-24. T. aurea. 23. Isolateral and amphistomatic mesophyll, with secondaries veins slightly spaced from each other. Note the stomata (arrows) at the same level of the other epidermal cells. 24. Margin. Note the thick-walled subepidermal cells. Bars $=50 \mu \mathrm{m}$. 

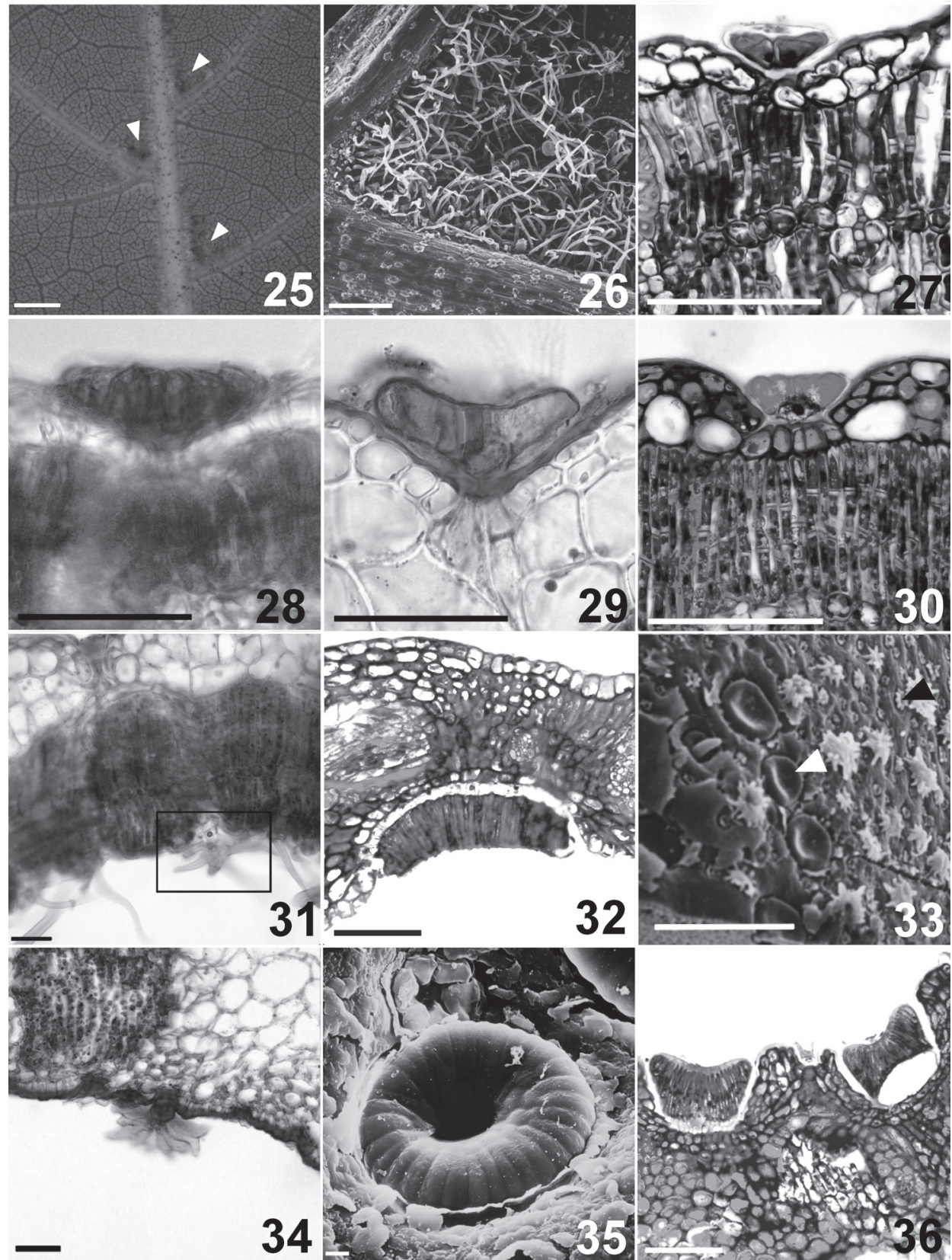

Figuras 25-36. Anexos epidérmicos da lâmina foliar de espécies de Handroanthus e Tabebuia. 25-26. H. roseo-albus. 25. Visão geral da disposição das domácias (setas). 26. Domácias revestidas por tricomas filiformes unisseriados. 27-36. Tricomas cuticularizados, exibindo formas variadas. 27-30. Tricoma escamiforme em H. chrysotrichus (27), H. heptaphyllus (28), H. impetiginosus (29) e H. ochraceus (30). 31. Tricoma estrelado (quadro) em H. ochraceus. 32. Tricoma pateliforme em H. serratifolius. 33-36. T. aurea. 33. Superfície foliar exibindo tricomas pateliformes (seta branca) e em roseta (seta preta). 34. Detalhe de um tricoma em roseta. 35-36. Detalhe da superfície (35) e da anatomia (36) de um tricoma pateliforme. Fotomicrografias em 25-32, 34 e 36; eletromicrografias em 26, 33 e 35. Barras $=2$ $\mathrm{mm}(25), 500 \mu \mathrm{m}(26,33), 50 \mu \mathrm{m}(27-32,34,36), 10 \mu \mathrm{m}(35)$.

Figures 25-36. Foliar epidermal appendages of Handroanthus and Tabebuia species. 25-26. H. roseo-albus. 25. General view of domatia distribution (arrows). 26. Domatia covered by uniseriate filiform trichomes. 27-36. Different types of trichomes. 27-30. Squamiform trichomes in H. chrysotrichus (27), H. heptaphyllus (28), H. impetiginosus (29) and H. ochraceus (30). 31. Stellate trichome (framed) in H. ochraceus. 32. Patelliform trichome in H. serratifolius. 33-36. T. aurea. 33. General view of patelliform trichomes (white arrow) and trichomes in rosette (black arrow). 34. Detail of a trichome in rosette. 35-36. Surface (35) and anatomical (36) details of a patelliform trichome. Photomicrographs in 25-32, 34 and 36; electron micrographs (SEM) in 26, 33 and 35. Bars = $2 \mathrm{~mm}(25), 500 \mu \mathrm{m}(26,33), 50$ $\mu \mathrm{m}(27-32,34,36), 10 \mu \mathrm{m}(35)$. 
Tabela 1. Caracteres anatômicos diagnósticos observados em espécies de Handroanthus e Tabebuia. Os sinais + e - significam, respectivamente, presença e ausência. Abreviações: $\mathrm{Hc}=H$. chrysotrichus; $\mathrm{Ho}=H$. ochraceus; $\mathrm{Hs}=H$. serratifolius $; \mathrm{Ta}=T$. aurea $; \mathrm{Hr}-\mathrm{a}=H$. roseo-albus; $\mathrm{Hh}=H$. heptaphyllus; $\mathrm{Hi}=H$. impetiginosus .

Table 1. Diagnostic anatomical characters observed on leaf of Handroanthus and Tabebuia species. Signs + and - indicate, respectively, presence and absence. Abbreviations: Hc = H. chrysotrichus; Ho = H. ochraceus; $\mathrm{Hs}=H$. serratifolius $; \mathrm{Ta}=T$. aurea $; \mathrm{Hr}-\mathrm{a}=H$. roseoalbus $; \mathrm{Hh}=H$. heptaphyllus $; \mathrm{Hi}=H$. impetiginosus .

\begin{tabular}{|c|c|c|c|c|c|c|c|c|}
\hline & \multirow{3}{*}{ Caracteres } & \multicolumn{7}{|c|}{ Espécies } \\
\hline & & \multicolumn{4}{|c|}{ Ipês-amarelos } & \multirow{2}{*}{$\frac{\text { Ipê-branco }}{\mathrm{Hr}-\mathrm{a}}$} & \multicolumn{2}{|c|}{ Ipês-roxos } \\
\hline & & $\mathrm{Hc}$ & Ho & Hs & $\mathrm{Ta}$ & & $\mathrm{Hh}$ & $\mathrm{Hi}$ \\
\hline \multirow{9}{*}{ Lâmina foliar } & Epiderme uni a bisseriada & + & - & + & + & - & + & + \\
\hline & Anfiestomática & - & - & - & + & - & - & - \\
\hline & Estômatos protuberantes na face abaxial & + & + & - & - & + & + & + \\
\hline & Domácias & + & - & + & - & + & + & + \\
\hline & Mesofilo dorsiventral & - & - & + & - & + & + & - \\
\hline & Parênquima paravenal & + & - & - & - & - & - & - \\
\hline & Ondulações pronunciadas na face abaxial & + & + & - & - & - & - & - \\
\hline & Feixes vasculares pouco espaçados & - & - & - & + & - & - & - \\
\hline & Margem com células parenquimáticas lignificadas & - & + & + & + & + & + & - \\
\hline \multirow{3}{*}{ Pecíolo } & Epiderme papilosa & + & - & - & + & - & - & - \\
\hline & Fibras na região interna do floema & + & - & - & - & - & - & - \\
\hline & Medula oca & - & - & - & - & - & + & + \\
\hline
\end{tabular}

(ipê-branco medicinal) apresentou características anatômicas foliares muito semelhantes às das demais espécies; entretanto, pode ser diagnosticado pelo formato externo do pecíolo (cilíndrico com duas projeções) e pela epiderme unisseriada.

A variação no tipo de mesofilo (isolateral e dorsiventral), relatada para as espécies de Handroanthus e Tabebuia neste trabalho e para aquelas estudadas por Souza \& Oliveira (2004), contraria a informação encontrada em Metcalfe \& Chalk (1950), de que as folhas de espécies de Bignoniaceae são dorsiventrais, com registro de mesofilo isolateral apenas no gênero Kigelia.

O tipo, a distribuição e a anatomia dos tricomas e das domácias merecem estudos mais detalhados em Handroanthus e Tabebuia, já que tais estruturas têm sido utilizadas como caracteres com valor taxonômico em membros de Hippocrateoideae, uma das subfamílias de Celastraceae (Gomes et al. 2005) e para representantes de Forsteronia, um gênero de Apocynaceae (Rio et al. 2005).

Caracteres considerados conservativos para Handroanthus incluem periciclo esclerenquimático e epiderme unisseriada no pecíolo; e epiderme cuticularizada, com estômatos na face abaxial e tricomas de formas variadas na lâmina foliar. Segundo Sampaio et al. (2007), caracteres provenientes do tegumento da semente de H. ochraceus (= Tabebuia ochracea), como exotesta lignificada, com células alongadas periclinalmente, mesotesta parenquimática com poucos grãos de amido, também são considerados conservativos para o grupo.

Os dados obtidos neste trabalho mostraram que a anatomia da lâmina foliar e do pecíolo provê bons caracteres diagnósticos para os ipês brasileiros (Handroanthus e Tabebuia), podendo ser utilizados como subsídios a delimitações infragenéricas e genéricas. Embora poucos trabalhos tenham utilizado a anatomia como subsídio à taxonomia em Bignoniaceae, as espécies Anemopaegma arvense, Jacaranda decurrens e Zeyheria montana foram distinguidas pela presença e pelo tipo de tricomas na lâmina foliar e no pecíolo, pela espessura da cutícula foliar e pelo tipo de mesofilo (Mauro et al. 2007). No gênero Handroanthus a anatomia das plântulas permitiu a distinção entre $H$. impetiginosus $(=T$. avellanedae) e $H$. chrysotrichus $(=T$. chrysotricha) (Souza \& Oliveira 2004), e a anatomia do pericarpo forneceu caracteres diagnósticos para H. chrysotrichus e H. ochraceus (Souza et al., 2005). 


\section{Agradecimentos}

Agradecemos a José Augusto Maulin e Maria Dolores Seabra Ferreira (Laboratório de Microscopia Eletrônica da FMRP/USP), a Mário Sadaiti Ogasawara (FCFRP/USP) e ao Dr. Rodrigo Augusto Santinelo Pereira (FFCLRP/USP) pelo auxílio técnico.

\section{Literatura citada}

Britton, N.L. 1915. Studies of West Indian plants. Bulletin of the Torrey Botanical Society 42: 372-379.

De Candolle, A.P. 1838. Revue sommaire de la famille des Bignoniaceae. Bibliothèque Universelle, Génève.

Dousseau, S., Alvarenga, A.A., Castro, E.M., Soares, R.P., Emrich, E.B.\& Melo,L.A. 2008. Anatomia foliar de Tabebuia serratifolia (Vahl) Nich. (Bignoniaceae) propagadas in vitro, in vivo e durante a aclimatização. Ciencia e Agrotecnologia 32: 1694-1700.

Gentry,A.H. 1992. Bignoniaceae - part II (Tribo Tecomeae). In: Flora Neotropica Monograph 25: 1-370.

Gerlach, D. 1969. Botanische mikrotechnik. Georg Thieme, Stuttgart.

Gomes, S.M.A., Silva, E.A.M., Azevedo, A.A., Lombardi, J.A.\& Vale,F.H.A. 2005. Anatomia foliar como subsídio à taxonomia de Hippocrateoideae (Celastraceae) no Sudeste do Brasil. Acta Botanica Brasilica 19: 945-961.

Johansen, D.A. 1940. Plant microtechnique. McGraw-Hill, New York.

Lorenzi, H. \& Matos, F.J.A. 2002. Plantas Medicinais no Brasil - nativas e exóticas. Instituto Plantarum de Estudos da Flora, Nova Odessa.

Lorenzi, H. 2002. Árvores brasileiras: manual de identificação e cultivo de plantas arbóreas do Brasil. Instituto Plantarum de Estudos da Flora, Nova Odessa.

Mattos, J.R. 1970. Handroanthus, um novo gênero para os "ipês" do Brasil. Loefgrenia 50: 1-4.

Mauro, C., Pereira, M.A.S., Silva, C.P., Missima, J., Ohnuki, T. \& Rinaldi, R.B. 2007. Estudo anatômico das espécies de cerrado Anemopaegma arvense (Vell.) Stellf. ex de Souza (catuaba), Zeyheria montana Mart. (bolsa-de-pastor) e Jacaranda decurrens Chamisso (caroba) - Bignoniaceae. Revista Brasileira de Farmacognosia 17: 262-265.

Metcalfe, C.R. \& Chalk, L. 1950. Anatomy of the Dicotyledons: leaves, stem, and wood in relation to taxonomy with notes one economic uses. v. 2. Clarendon Press, Oxford.

Olmstead,R.G.\& Grose, S.O. 2007. Taxonomic revisions in the polyphyletic genus Tabebuia s. 1. (Bignoniaceae). Systematic Botany 32: 660-670.

Rio, M.C.S., Kinoshita, L.S. \& Castro, M.M. 2005. Anatomia foliar como subsídio para a taxonomia de espécies de Forsteronia G. Mey. (Apocynaceae) dos cerrados paulistas. Revista Brasileira de Botânica 28: 713-726.

Rodrigues, V.E.G. \& Carvalho, D.A. 2001 . Levantamento etnobotânico de plantas medicinais no domínio do cerrado na região do alto Rio Grande - MG. Ciência e Agrotecnologia 25: 102-123.

Sampaio, D.S., Costa, M.E. \& Paoli, A.A.S. 2007 Ontogenia da semente de Tabebuia ochracea (Cham.) Standl. (Bignoniaceae). Revista Brasileira de Botânica 30: 289-302.

Souza, L.A. \& Oliveira, J.H.G. 2004. Morfologia e anatomia das plântulas de Tabebuia avellanedae Lor. ex Griseb e T. chrysotricha (Mart. ex DC.) Standl. (Bignoniaceae). Acta Scientiarum (Biological Sciences) 26: $217-226$.

Souza, L.A., Iwazaki, M.C. \& Moscheta, I.S. 2005. Morphology of the pericarp and seed of Tabebuia chrysotricha (Mart. ex DC.) Standl. (Bignoniaceae). Brazilian Archives of Biology and Technology 48: 407-418.

Souza, V.C. \& Lorenzi, H. 2005. Botânica sistemática: guia ilustrado para identificação das famílias de Angiospermas da flora brasileira. Instituto Plantarum de Estudos da Flora, Nova Odessa. 